\title{
Nutritional Management of Gastroesophageal Reflux Among Infants in the Philippines: Insights From Real-World Evidence
}

\author{
Felizardo Gatcheco ${ }^{\mathrm{a}}$, Maria Imelda Vitug Sales ${ }^{\mathrm{b}}$, Grace Battad ${ }^{\mathrm{c}}$, Marilou Tan ${ }^{\mathrm{d}}$, \\ Ma Cecilia D. Gloria ${ }^{\mathrm{e}}$, Urszula Kudlaf, Leilani Muhardis, h
}

\begin{abstract}
Background: The objective of the study was to describe the clinical course of infants with pediatrician-diagnosed gastroesophageal regurgitation (GER), after changing to an infant anti-regurgitation formula.

Methods: Information on frequency and volume of regurgitation, and disease progression were collected from mothers of 0- to 12-monthold Filipino infants with GER at baseline and 1 month after a pediatrician prescribed-formula containing carob bean gum, galacto-oligosaccharides and partially hydrolyzed whey protein for 14 days.

Results: Eighty-nine infants aged $\leq 6$ months and 40 aged $7-12$ months old were enrolled. The most frequently reported amount of baseline regurgitation was half of the total feed (29 (33\%) younger infants and 17 (43\%) older infants). Baseline regurgitation frequency ranged from $1-3$ times/day $(45(51 \%)$ and $21(52 \%))$ to $4-6$ times/day (33 (37\%) and $14(35 \%))$ and 7 - 9 times/day (11 $(12 \%)$ and five $(13 \%))$. Regurgitation after 1-day consumption was resolved in $16(18 \%)$ and $8(20 \%)$ and in $57(64 \%)$ and $31(78 \%)$ younger and older infants at 14 days. Forty-one (32\%) infants still had regurgitation episodes after a 14-day trial with decreased frequency and volume; three (7\%) infants did not show any improvement, while one (1\%) infant had increased amount of regurgitation. No medicine was given to study participants. Parent-reported sleep disturbance decreased in three (37\%) younger infants and $25(63 \%)$ older infants.
\end{abstract}

Conclusion: Nutrition intervention has effectively improved symp-

Manuscript submitted July 15, 2019, accepted August 9, 2019

a Jose R. Reyes Memorial Medical Center, Manila, Philippines

${ }^{b}$ Makati Medical Center, Manila, Philippines

'University of the East Ramon Magsaysay Medical Center, Manila, Philippines

dPhilippine Children Medical Center, Manila, Philippines

eMarketing Department, FrieslandCampina, Manila, Philippines

${ }^{\mathrm{f}}$ FrieslandCampina, Amersfoort, the Netherlands

gMedical Affairs Department, FrieslandCampina AMEA Pte Ltd, Singapore

${ }^{\mathrm{h}}$ Corresponding Author: Leilani Muhardi, FrieslandCampina AMEA Pte Ltd,

3 Temasek Avenue, \#11-01 Centennial Tower, 039190, Singapore.

Email: leilani.muhardi@frieslandcampina.com

doi: https://doi.org/10.14740/ijcp338 tom and quality of life among infants with GER within 14 days. Information on underlying conditions among those with unresolved symptoms are needed.

Keywords: Anti-regurgitation; Carob bean gum; Galacto-oligosaccharides; Gastroesophageal regurgitation; Infants; Partially hydrolyzed whey protein; Special infant milk formula

\section{Introduction}

Gastroesophageal reflux (GER) is one of the most common digestive problems in the first months of life and decreases the quality of life in formula-fed infants [1]. The worldwide prevalence of infantile GER is $30 \%$ [1] with a peak of $67-87 \%$ at 2 - 4 months of life [2]. A survey conducted in China, Malaysia, Russia and Vietnam showed that this disorder affected $61 \%$ infants aged between 0 and 3 months, $32 \%$ infants aged 3 - 6 months and 8\% infants aged 6 - 12 months [3].

Infantile GER is usually diagnosed using the new symptom-based Rome IV criteria for infants and toddlers [2]. In parallel, the North American Society for Pediatric Gastroenterology, Hepatology, and Nutrition (NASPGHAN) and the European Society for Pediatric Gastroenterology, Hepatology, and Nutrition (ESPGHAN) have developed an international consensus to help the pediatricians and pediatric subspecialists in the diagnosis and management of infantile GER [4]. A joint consensus between NASPGHAN and ESPGHAN jointly recommends non-pharmacological intervention with lifestyle changes in the infants such as thickened feedings, consumption of special anti-regurgitation formulas and positioning after meals [4].

Data support the use of thickened formula with added functional ingredients like carob bean gum $(\mathrm{CBG})$, galacto-oligosaccharides (GOS) and partially hydrolyzed whey proteins (PHW) [5-12]. CBG is an indigestible but fermentable fiber with prebiotic effects $[10,13]$, in which its mechanism of action involves increasing the viscosity of food and milk at a safe therapeutic level of $0.5 \mathrm{~g} / 100 \mathrm{~mL}$ [6], resulting in a reduction in total and acid reflux $[10,13]$. Moreover, CBG may promote the development of more diverse microbiota and a lower $\mathrm{pH}$ as compared to rice or maize starch [10]. GOS have been re- 
Table 1. Nutritional Profile of the Special Anti-Regurgitation Infant Milk Formula

\begin{tabular}{|c|c|c|c|}
\hline Ingredients & Unit & Per $100 \mathrm{~g}$ & Per 100 kcal \\
\hline Protein & $\mathrm{g}$ & 10.7 & 2.1 \\
\hline Fat & $\mathrm{g}$ & 27.1 & 1.4 \\
\hline Alpha-linolenic acid & $\mathrm{mg}$ & 470 & 93 \\
\hline AA & $\mathrm{mg}$ & 53 & 10 \\
\hline Galacto-oligosaccharides & $\mathrm{g}$ & 0.4 & 0.08 \\
\hline Galactomannan & $\mathrm{g}$ & 2.5 & 0.5 \\
\hline \multicolumn{4}{|l|}{ Mineral } \\
\hline Calcium & $\mathrm{mg}$ & 385 & 76 \\
\hline Copper & $\mu \mathrm{g}$ & 380 & 75 \\
\hline Potassium & $\mathrm{mg}$ & 560 & 111 \\
\hline Chloride & $\mathrm{mg}$ & 335 & 66 \\
\hline Magnesium & $\mathrm{mg}$ & 49 & 97 \\
\hline Zinc & $\mathrm{mg}$ & 4.4 & 0.87 \\
\hline
\end{tabular}

ported to have bifidogenic effects, promote the maturity of the gastrointestinal tract and improve the stool consistency at 0.24 $\mathrm{g} / \mathrm{L}, 0.4 \mathrm{~g} / \mathrm{L}$ and $0.5 \mathrm{~g} / \mathrm{L}[7-9,14]$. In parallel, PHW has been associated with fast gastric emptying time and improve digestion in infants [11].

No real-world data are available, for example, on the duration to symptom resolution in infants suffering from GER. In this context, a survey was conducted to understand the clinical course of Filipino infants ( 0 - 12 months) who were suffering from infantile GER diagnosed by a pediatrician and received an anti-regurgitation infant milk formula containing $\mathrm{CBG}$, GOS and PHW.

\section{Patients and Methods}

\section{Design and data collection}

An observational and questionnaire-based survey was conducted between November 2017 and June 2018 in the Greater Manila Area, North Luzon and South Luzon in the Philippines. Fifty pediatricians were asked to recommend a 14-day trial of a special anti-regurgitation infant milk formula (Frisolac ${ }^{\circledR} A R$, FrieslandCampina, the Netherlands) containing CBG, GOS and PHW to infants aged between 0 and 12 months and diagnosed with GER (Table 1). Regurgitation in this study was defined as any occurrence of refluxing gastric contents after feeds more than three times a day but no associated historical or physical examination findings were abnormal. Exclu- sion criteria were exclusively breastfed infants, normal healthy infants without any signs and symptoms of regurgitation and infants with obvious underlying structural deformities related to regurgitation.

Institutional Review Board approval was not obtained as this is a survey with products already in the market as part of the nutrition management. Ethical compliance with human/ animal study was not obtained. Verbal consent was obtained from the survey's participants prior to their participation but not recorded. The survey instrument, a questionnaire, was completed orally with the parents and filled by the pediatricians at baseline, 14 days and 30 days after a special nutrition intervention to evaluate the improvement of the symptoms using the same tool. No information could be obtained unless the parents agreed to participate, and no data could be filled by pediatricians unless released by the parents themselves. The questionnaire collected frequency and volume of regurgitation, progression of the disease and other complaints including the reported volume of regurgitation (Supplementary 1, www. theijcp.org).

The product used for the nutritional management of GER has received regulatory approval and is available in the Philippines since 2016 and in other markets since 2010.

\section{Statistical analyses}

Descriptive analyses were performed using counts and frequencies (n, \%) and using IBM SPSS version 24 for Windows release (SPSS, Statistical Packages for Social Sciences, an 


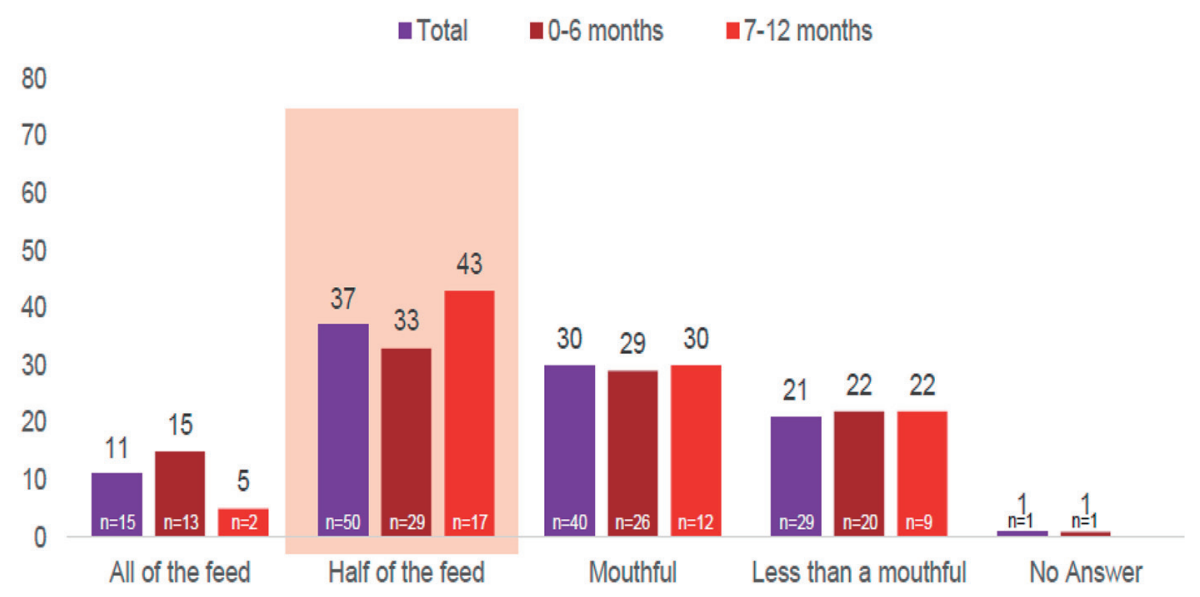

Figure 1. Reported average of regurgitation volume at baseline (\%). Total interviews $(n=135) ; 0-6$ months $(n=89) ; 7-12$ months $(n=40)$.

IBM Statistical Software, IBM Corp., Armonk, NY).

\section{Results}

\section{Patients demographic}

A total of 135 infants diagnosed with GER were prescribed the special infant formula during the survey period. Six patients were excluded from the analysis because four patients did not meet the selection criteria (aged $1-3$ years), and pediatricians did not provide the date of birth or the age of two patients. Therefore, data of 129 eligible infants ( 0 - 12 months old) were analyzed: 89 (69\%) infants aged 0 - 6 months and $40(31 \%)$ infants aged $7-12$ months.

\section{Baseline characteristics}

At baseline, 45 (51\%) younger infants aged 0 - 6 months and $21(52 \%)$ older infants aged $7-12$ months regurgitated $1-3$ times a day. Thirty-three (37\%) younger infants and $14(35 \%)$ older infants regurgitated $4-6$ times a day. A regurgitation frequency of 7 - 9 times a day was reported in $11(12 \%)$ younger infants and five (13\%) older infants.

The most frequently reported amount of regurgitation was half of the total feed in $29(33 \%)$ younger infants and $17(43 \%)$ older infants, followed by a mouthful in $26(29 \%)$ younger infants and $12(30 \%)$ older infants. All of the feed was regurgitated by $13(15 \%)$ younger infants and two $(5 \%)$ older infants (Fig. 1).

Endline characteristics after using the special infant formula

After 1 day of special formula consumption, 16 (18\%) younger infants and eight $(20 \%)$ older infants had no more regurgitation. No regurgitation at the frequency of $7-9$ episodes of regurgitation was reported and the number of younger infants regurgitating 4 - 6 times daily decreased to eight $(9 \%)$. More infants $(\mathrm{n}=65 ; 73 \%)$ were regurgitating 1 - 3 times daily; a similar pattern was observed for the older age group (7 - 12 months) (Fig. 2a). Likewise, the reported number of infants regurgitating half of the total feed decreased to $12(13 \%)$ in the 0 - to 6-month age group and to one (3\%) in the 7- to -12-month age group. More infants $(n=52(58 \%)$ in younger and $n=25$ $(62 \%)$ in older age groups) reported regurgitating less than a mouthful (Fig. 2b).

Between day 1 and day 5 of special formula consumption, decreased frequency and amount of regurgitation was more evident. More infants $(n=29(73 \%)$ in younger and $n=47(53 \%)$ in older age groups) were reported to have a decreased volume of regurgitation. After 14 days, regurgitation was completely resolved among the majority of the patients: 57 (64\%) younger infants and 31 (78\%) older infants. However, 41 (32\%) infants continued regurgitation episodes after a 14-day trial but the frequency and volume of regurgitation decreased in 26 (64\%) younger infants and 24 (59\%) older infants. Three (7\%) infants did not show any improvement, and one (1\%) infant had an increased amount of regurgitated feed (Fig. 3).

On the quality of life's questionnaire, parent reported decreased sleep disturbance for $33(37 \%)$ younger infants and $25(63 \%)$ older infants and decreased incessant crying for 45 (51\%) younger infants and $26(65 \%)$ older infants. Additionally, bowel movement was improved in 48 (54\%) younger infants and $24(60 \%)$ older infants, and longer feeding time was reported among $27(30 \%)$ younger infants and $13(33 \%)$ older infants (Fig. 4).

\section{Discussion}

This survey revealed that GER-related symptoms such as regurgitation still occur among infants aged 7 - 12 months (31\% of all infants) [15]. Generally, GER peaks at the age of 2 - 4 months $[2,15]$ and should resolve by 12 months of age. 
a

None at all $1-3 \mathrm{x}$ a day $\quad 4-6 \mathrm{x}$ a day $\square$-9x a day
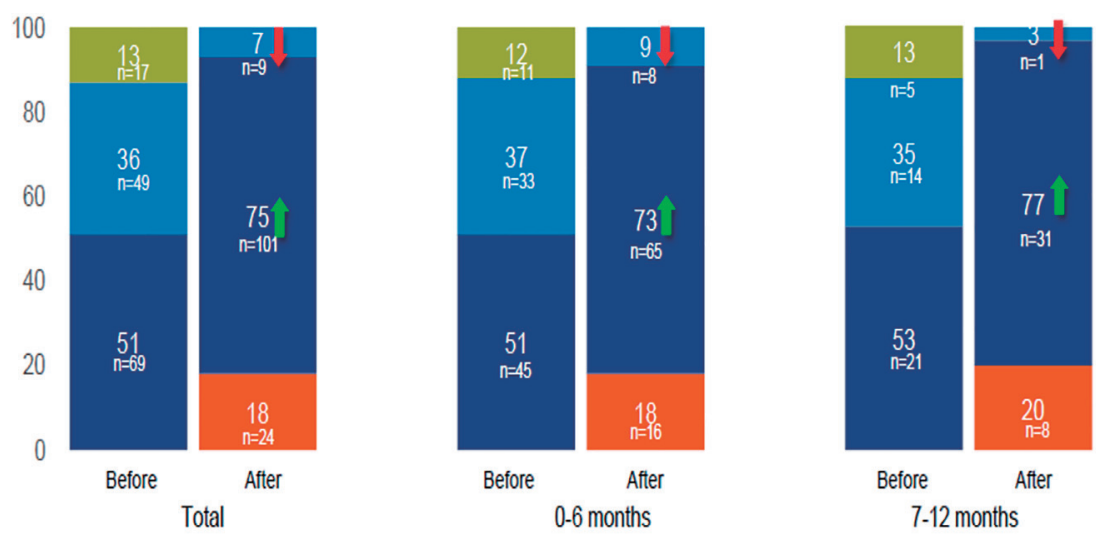

When improvement After 1-day trial After 1-day trial After 1.5 day trial
was observed (mode):

b

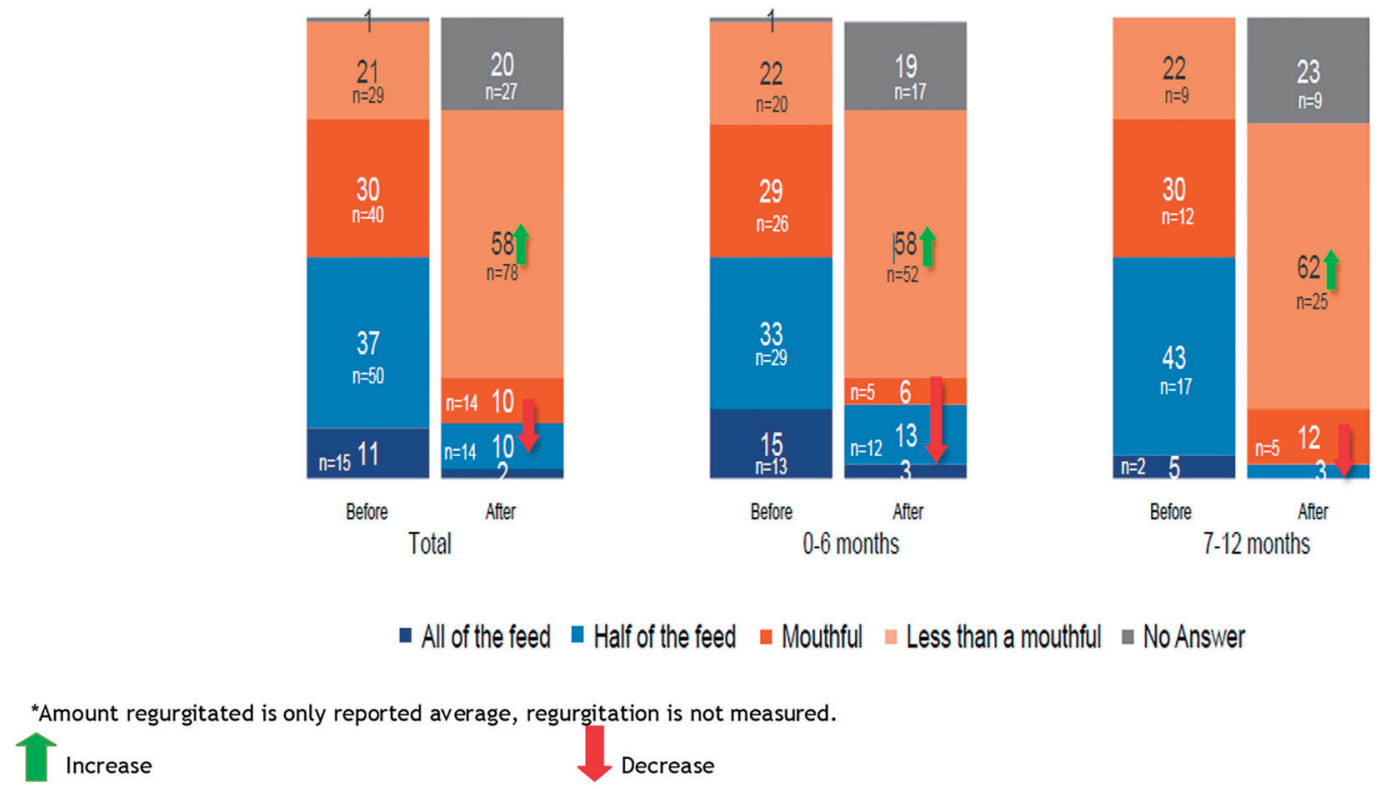

Figure 2. (a) Average frequency of regurgitation after using the special infant formula (\%). (b) Average amount usually regurgitated after using the special infant formula (\%). Total interviews $(n=135) ; 0$ - 6 months $(n=89) ; 7-12$ months $(n=40)$.

Nutritional intervention seems effective in the management of GER without any medicine as one out of five infants no longer had regurgitation within 1 day of shifting to the anti-regurgitation formula; outcomes tended to be similar in younger and older infants. Furthermore, the amount of regurgitation decreased to less than a mouthful across all ages as claimed by the patients' mothers. Further symptom's resolution was reported between 1 and 5 days of usage as half of the infants showed an improvement in the frequency and amount of regurgitation. Such effects are likely to have a positive influence on parental anxiety and quality of life especially among first-time parents $[16,17]$.
The percentage of the study participants without any regurgitation increased from $13 \%$ at days $1-5$, to $18 \%$ at days 6 -10 , to $39 \%$ at days $11-14$ and to an average of $70 \%$ ( $64 \%$ of younger infants and $78 \%$ of older infants) at 14 days of using this formula (Fig. 3a).

The consumption of the anti-regurgitation infant milk formula containing CBG, GOS and PHW was also associated with an improvement in the quality of life of the infants as incessant crying and sleep disturbances. Regular and softer stools were also reported particularly among the infants aged 7 - 12 months consuming the formula as this could be effective in the management of multiple symptoms of functional gastro- 
$\mathbf{a}$

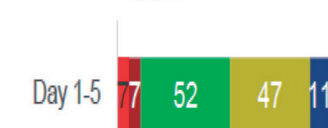

Day 6-10

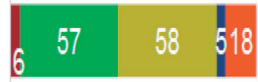

Day $11-14 \quad 37 \quad 44 \quad 10 \quad 39$
0-6 months
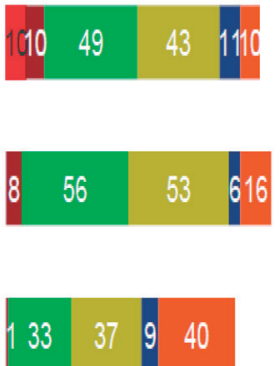

7-12 months
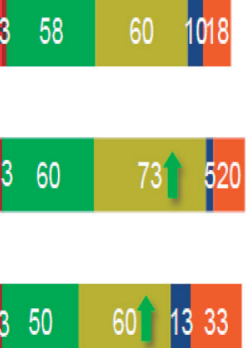

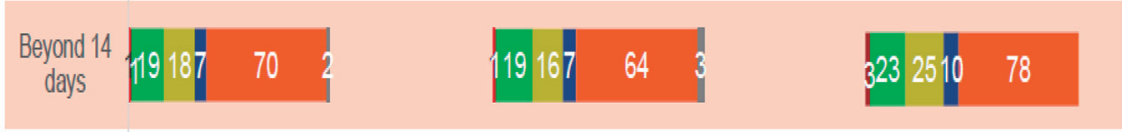

\begin{tabular}{|c|c|c|c|}
\hline - Increased frequency & - Increased amount & -Decreased frequency & Decreased amount \\
\hline No change & Completely gone & nNo Answer & \\
\hline
\end{tabular}

b Total $0-6$ months 7-12 months

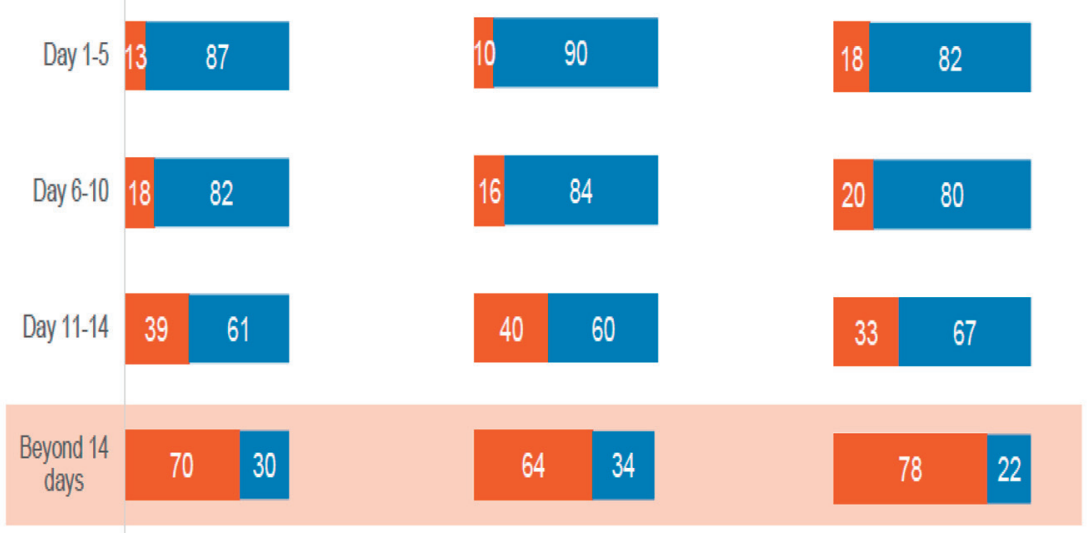

Completely Gone -Still Regurgitating

Figure 3. (a, b) Symptoms' improvement at 14 days of consumption (\%). Total interviews $(n=135) ; 0-6$ months $(n=89) ; 7-12$ months $(n=40)$.

intestinal disorders in early life [1].

The results of this observational survey are consistent with the findings of previous clinical studies on anti-regurgitation infant milk formulas containing the same thickening agents $[18,19]$. A randomized and partly double-blind clinical trial compared the same infant milk formula at $0.33 \mathrm{~g} / 100 \mathrm{~mL}$ of cold CBG (formula A, Frisolac ${ }^{\circledR}$ AR) with two other formulas at $0.45 \mathrm{~g} / 100 \mathrm{~mL}$ of cold or hot $\mathrm{CBG}$ (formulas $\mathrm{B}$ and $\mathrm{C}$ ). Formula A was shown to be more effective in decreasing the occurrence of reflux episodes and improving clinical symptoms of GER (decreased night cough, crying and frequency of vomiting) after 2 weeks of intervention [18]. Also in a prospective, double-blind, randomized cross-over trial conducted in
115 formula-fed infants ( 2 weeks to 5 months old), a formula containing $\mathrm{CBG}$ at $0.33 \mathrm{~g} / \mathrm{L}$ and hydrolyzed protein was more effective in reducing the number and volume of regurgitations compared to another formula containing a nonhydrolyzed protein and less CBG $(0.33 \mathrm{~g} / \mathrm{L})[11]$.

This survey has some limitations. First, it was not a randomized trial, thus it did now allow any direct comparison with a control group. Second, only children from three regions of the Philippines were included; however, our population can be seen as representative of an urban population. Third, this survey might be affected by the self-reporting bias as parents tend to over-report behaviors and symptoms viewed as appropriate by the researchers or doctors, and to under-report what is per- 


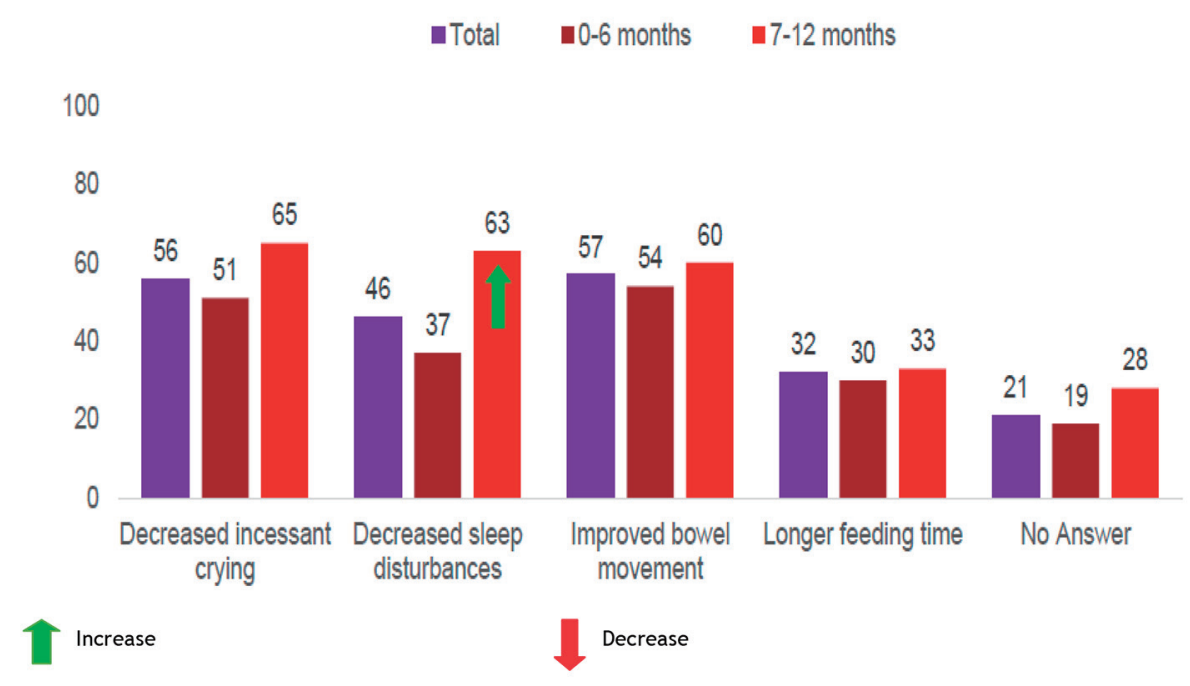

Figure 4. Other effects in 14-day trial (\%). Total interviews $(n=135) ; 0$ - 6 months $(n=89) ; 7-12$ months $(n=40)$.

ceived to be inappropriate. Indeed, self-reporting bias is common in dietary surveys of infant feeding practices, especially those conducted verbally [20]. However, the same questionnaire was used at various time points in the survey to evaluate the improvement of the symptoms using the same tool. Fourth, data on the amount of formula given at each feeding, feeding methods (i.e. allowing the infants to burp and rest during the feeding) and their uniformity, and whether the infants were receiving other food items during the feeding with the formula including breast milk are not available. Regardless of these limitations, this survey described real-world insights on the time for symptom's resolution and the effectiveness of nutrition management of GER among infants in the Philippines without any pharmacological intervention. It also provided a window of opportunity for non-medical based intervention in functional regurgitation leading to improved parents' quality of life.

To conclude, this survey investigated the clinical course of Filipino infants suffering from infantile GER, after changing to a special infant formula designed to relieve GER. A formula designed for management of regurgitation and thickened with CBG, GOS and PHW effectively improved regurgitation symptoms and patient's quality of life within the 14 days of consumption. Underlying conditions among infants who still had symptoms after 14 days need to be investigated, especially that prolonged symptoms of functional gastrointestinal disorders in early life could lead to increased risk of these disorders in later life [21].

\section{Acknowledgments}

The authors are thankful for the infants and their families who participated in this survey. The authors also thank Content Ed Net Singapore for providing editorial and medical writing assistance for the preparation of this manuscript. They also thank GfK Philippines Cooperation for data collection and analysis.

\section{Financial Disclosure}

The authors, Felizardo Gatcheko, Maria Imelda Vitug Sales, Grace Battad and Marilou Tan received an educational grant from Friesland Campina to review and publish the survey's result.

\section{Conflict of Interest}

Ma Cecilia D. Gloria, Urszula Kudla and Leilani Muhardi are employees of Friesland Campina.

\section{Informed Consent}

Verbal consent was obtained from the survey's participants prior to the survey.

\section{Author Contributions}

Ma Cecilia D. Gloria designed and monitored the study implementation. Felizardo Gatcheko, Maria Imelda Vitug Sales, Grace Battad, Marilou Tan, Urszula Kudla and Leilani Muhardi reviewed the study results and interpretation. All authors provided inputs and agreed on the final version of the manuscript.

\section{References}

1. Bellaiche M, Oozeer R, Gerardi-Temporel G, Faure C, Vandenplas Y. Multiple functional gastrointestinal disorders are frequent in formula-fed infants and decrease their quality of life. Acta Paediatr. 2018;107(7):1276-1282.

2. Zeevenhooven J, Koppen IJ, Benninga MA. The New 
Rome IV criteria for functional gastrointestinal disorders in infants and toddlers. Pediatr Gastroenterol Hepatol Nutr. 2017;20(1):1-13.

3. Friso Healthcare Professional Survey. Cimigo 2010. Friso survey conducted in China, Malaysia, Russia and Vietnam in 2010 amongst 541 healthcare professionals.

4. Rosen R, Vandenplas Y, Singendonk M, Cabana M, DiLorenzo C, Gottrand F, Gupta S, et al. Pediatric gastroesophageal reflux clinical practice guidelines: joint recommendations of the North American Society for Pediatric Gastroenterology, Hepatology, and Nutrition and the European Society for Pediatric Gastroenterology, Hepatology, and Nutrition. J Pediatr Gastroenterol Nutr. 2018;66(3):516-554.

5. Horvath A, Dziechciarz P, Szajewska H. The effect of thickened-feed interventions on gastroesophageal reflux in infants: systematic review and meta-analysis of randomized, controlled trials. Pediatrics. 2008;122(6):e12681277.

6. Meunier L, Garthoff JA, Schaafsma A, Krul L, Schrijver J, van Goudoever JB, Speijers G, et al. Locust bean gum safety in neonates and young infants: an integrated review of the toxicological database and clinical evidence. Regul Toxicol Pharmacol. 2014;70(1):155-169.

7. Ben XM, Li J, Feng ZT, Shi SY, Lu YD, Chen R, Zhou $\mathrm{XY}$. Low level of galacto-oligosaccharide in infant formula stimulates growth of intestinal Bifidobacteria and Lactobacilli. World J Gastroenterol. 2008;14(42):65646568.

8. Giovannini M, Verduci E, Gregori D, Ballali S, Soldi S, Ghisleni D, Riva E, et al. Prebiotic effect of an infant formula supplemented with galacto-oligosaccharides: randomized multicenter trial. J Am Coll Nutr. 2014;33(5):385393.

9. Fanaro S, Marten B, Bagna R, Vigi V, Fabris C, PenaQuintana L, Arguelles F, et al. Galacto-oligosaccharides are bifidogenic and safe at weaning: a double-blind randomized multicenter study. J Pediatr Gastroenterol Nutr. 2009;48(1):82-88.

10. Gonzalez-Bermudez CA, Lopez-Nicolas R, Peso-Echarri P, Frontela-Saseta C, Martinez-Gracia C. Effects of different thickening agents on infant gut microbiota. Food Funct. 2018;9(3):1768-1778.
11. Vandenplas Y, Leluyer B, Cazaubiel M, Housez B, Bocquet A. Double-blind comparative trial with 2 antiregurgitation formulae. J Pediatr Gastroenterol Nutr. 2013;57(3):389-393.

12. Indrio F, Riezzo G, Giordano P, Ficarella M, Miolla MP, Martini S, Corvaglia L, et al. Effect of a partially hydrolysed whey infant formula supplemented with starch and lactobacillus reuteri DSM 17938 on regurgitation and gastric motility. Nutrients. 2017;9(11):1181.

13. Herrewegh A. Effect van Frisovom flesvoeding op darmflora van zuigelingen. (Unpublished report in Dutch). NIZO report no. E2000/33; 2000.

14. Stewart ML, Schroeder NM. Dietary treatments for childhood constipation: efficacy of dietary fiber and whole grains. Nutr Rev. 2013;71(2):98-109.

15. Hegar B, Satari DH, Sjarif DR, Vandenplas Y. Regurgitation and gastroesophageal reflux disease in six to nine months old Indonesian infants. Pediatr Gastroenterol Hepatol Nutr. 2013;16(4):240-247.

16. Salvatore S, Abkari A, Cai W, Catto-Smith A, Cruchet S, Gottrand F, et al. Review shows that parental reassurance and nutritional advice help to optimise the management of functional gastrointestinal disorders in infants [published online ahead of print, 2018 May 25]. Acta Paediatr. 2018;107(9):1512-1520.

17. Gonzalez Ayerbe JI, Hauser B, Salvatore S, Vandenplas Y. Diagnosis and management of gastroesophageal reflux disease in infants and children: from guidelines to clinical practice. Pediatr Gastroenterol Hepatol Nutr. 2019;22(2):107-121.

18. Georgieva M, Manios Y, Rasheva N, Pancheva R, Dimitrova E, Schaafsma A. Effects of carob-bean gum thickened formulas on infants' reflux and tolerance indices. World J Clin Pediatr. 2016;5(1):118-127.

19. Vivatvakin B, Buachum V. Effect of carob bean on gastric emptying time in Thai infants. Asia Pac J Clin Nutr. 2003;12(2):193-197.

20. Donaldson S, Grant-Vallone E. Understanding self-report bias in organizational behavior research. J Bus Psychol. 2002;17:254-262.

21. Bonilla S, Saps M. Early life events predispose the onset of childhood functional gastrointestinal disorders. Rev Gastroenterol Mex. 2013;78(2):82-91. 